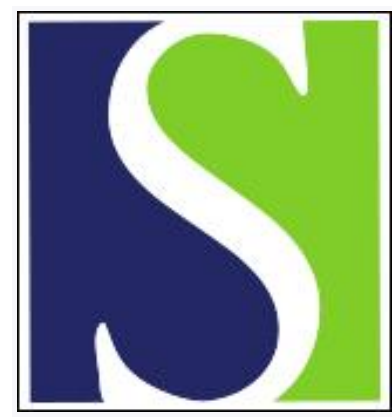

Scand J Work Environ Health 2021;47(4):296-305

https://doi.org/10.5271/sjweh.3951

Published online: 21 Mar 2021, Issue date: 01 May 2021

Impact of anxiety and depression disorders on sustained return to work after work-related musculoskeletal strain or sprain: a gender stratified cohort study

by Jones AM, Koehoorn M, Bültmann U, McLeod CB

In contrast to existing studies with small clinical samples and self-reported mental symptoms, this population-based cohort study includes clinically verified mental diagnoses and quantitative gender analysis. Findings suggest that disability management policy and practice should take both pre-existing and new onset anxiety and depression disorders into consideration after musculoskeletal injury as well as the intersection of gender with mental health.

Affiliation: School of Population and Public Health, 2206 East Mall, University of British Columbia, Vancouver, British Columbia, Canada, V6T 1Z3. andrea.jones@alumni.ubc.ca

Key terms: anxiety; British Columbia; Canada; cohort study; common mental disorder; comorbid condition; depression; gender-stratified; mental health; musculoskeletal disorder; musculoskeletal strain; return to work; RTW; sickness absence; work disability; workers' compensation; workplace

This article in PubMed: www.ncbi.nlm.nih.gov/pubmed/33744976

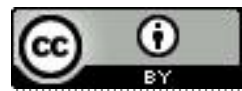




\title{
Impact of anxiety and depression disorders on sustained return to work after work- related musculoskeletal strain or sprain: a gender-stratified cohort study
}

\author{
by Andrea Marie Jones, PhD, ${ }^{1}$ Mieke Koehoorn, PhD, ${ }^{1}$ Ute Bültmann, PhD, ${ }^{2}$ Christopher B McLeod, PhD 1,3
}

\begin{abstract}
Jones AM, Koehoorn M, Bültmann U, McLeod CB. Impact of anxiety and depression disorders on sustained return to work after work-related musculoskeletal strain or sprain: a gender-stratified cohort study. Scand J Work Environ Health. 2021;47(4):296305. doi:10.5271/sjweh.3951
\end{abstract}

Objective The aim of this study was to examine the impact of anxiety and depression disorders on sustained return to work (RTW) for men and women with musculoskeletal strain or sprain.

Methods Accepted lost-time claims for spine and upper-extremity strain or sprain were extracted for workers in the Canadian province of British Columbia from 2009 to 2013 ( $\mathrm{N}=84$ 925). Pre-existing and new onset anxiety and depression disorders were identified using longitudinal health claims data. Probability of sustained RTW was analyzed using Cox proportional hazards models, stratified by gender and adjusted for potential confounders.

Results For pre-existing disorders, compared to men with no anxiety and no depression, men with anxiety only [hazard ratio (HR) $0.88,95 \%$ confidence interval (CI) 0.84-0.93], depression only (HR 0.94, 95\% CI 0.89-1.00), and anxiety and depression (HR 0.93, 95\% CI 0.90-0.97) had lower probabilities of sustained RTW in adjusted models. The same direction of effect was found for women, but anxiety only had a smaller effect size among women compared to men (HR anxiety only $0.95,95 \%$ CI $0.92-0.99$; HR depression only $0.98,95 \%$ CI $0.93-1.03$, HR anxiety and depression $0.94,95 \%$ CI $0.91-0.97$ ). Among men and women, new onset disorders were associated with lower probability of sustained RTW and the effect estimates were larger than for pre-existing disorders.

Conclusions Findings suggest that workers' compensation benefits and programs intended to improve RTW after musculoskeletal injury should take pre-existing and new onset anxiety and depression disorders into consideration and that gender-sensitive work disability strategies may be warranted.

Key terms British Columbia; Canada; common mental disorder; comorbid condition; mental health; RTW; sickness absence; work disability; workers' compensation; workplace.

Disability due to work-related musculoskeletal injury is a significant burden in Canada and other high-income countries around the world. In the Canadian province of British Columbia, musculoskeletal strain or sprain accounts for over half of all lost-time workers' compensation claims, $57 \%$ of all registered lost workdays due to work-related injury or illness, and \$347 million (CDN) in disability costs annually (1). Anxiety and depression disorders are common in workers with work-related musculoskeletal injury (2-4); however, evidence of their impact on sustained return to work (RTW) is incomplete.

Both pre-existing anxiety and depression disorders from before injury and new onset anxiety and depres- sion disorders that arise after the injury but before sustained RTW may contribute to poor RTW outcomes. Pre-existing anxiety or depression disorders may impact RTW through ongoing symptoms that persist after the injury or the exacerbation of pre-existing symptoms by the injury. Likewise, new onset disorders that arise after the injury may impact RTW through the emergence of new anxiety and depression symptoms. Mechanisms through which pre-existing and new onset anxiety and depression disorders could impact RTW after musculoskeletal injury include increased pain $(5,6)$, disruption to treatment or other rehabilitation activities $(7,8)$, low self-efficacy (9), unmet need for work accommodation,

1 Partnership for Work Health and Safety, School of Population and Public Health, University of British Columbia, Vancouver, British Columbia, Canada.

2 Department of Health Sciences, Community and Occupational Medicine, University Medical Center Groningen, University of Groningen, Groningen, The Netherlands.

3 Institute for Work and Health, Toronto, Ontario, Canada.

Correspondence to: Andrea Marie Jones, School of Population and Public Health, 2206 East Mall, University of British Columbia, Vancouver, British Columbia, Canada, V6T 1Z3. [E-mail: andrea.jones@alumni.ubc.ca] 
negative interactions with the compensation system (10) and stigmatization (11).

A 2008 systematic review found strong evidence that depression, and moderate evidence that anxiety, were not predictive of work outcomes after non-chronic, non-specific low-back pain (12). Inclusion of studies with short follow up time, small sample size, and varying anxiety and depression measurement methods often based on self-report may explain these null results. Other systematic reviews on this topic are limited by a lack of eligible studies, sometimes drawing conclusions on as few as one or two studies (13-17). Two recent Canadian prospective cohort studies also present inconsistent evidence. Depressive symptoms were associated with poor RTW in a sample of 332 Ontario workers (18), while neither anxiety nor depression were associated with RTW in a sample of 62 Quebec workers with work-related musculoskeletal injury (19).

Anxiety and depression disorders may impact men and women differentially following musculoskeletal injury. However, there is little-to-no empirical research on this topic. Prior studies have either adjusted or matched for gender effects, rather than quantifying them using stratification or interaction/effect modification methods (12-19). Possible reasons why anxiety and depression might be stronger risk factors for work disability after musculoskeletal injury among men compared to women include (i) a lower frequency of help seeking behavior among men, leading to under treatment and a lack of mental health-related support, that in turn allows symptoms to persist or grow in severity (20) and (ii) higher societal and personal valuation of income production and physical labor among men (20). The latter could result in greater feelings of loss or inadequacy among men during periods of work disability that in turn, further extenuate the condition of work disability, especially among men with pre-existing anxiety or depression or a diathesis for these disorders. Conversely, a greater number of hours spent on combined paid and unpaid work activities by women (21) could slow down women's recovery and deplete the emotional, physical, or motivational resources necessary to cope with work re-entry. Further, gendered differences in interactions with healthcare systems and services may contribute to differences in disability management and RTW outcomes. Each of these gendered characteristics, behaviors, and social roles could increase vulnerability to the psychological challenges of work disability and musculoskeletal injury or interfere with recovery and RTW capacity, especially when combined with anxiety or depression.

Research in this area can inform RTW policy and programming for musculoskeletal work injury by disability management systems, in particular the inclusion and use of mental health services, and the importance of gender-sensitive strategies for mental health and
RTW services. The objective of the current study was to address existing gaps and limitations in the literature by conducting a large population-based cohort study for injured workers in British Columbia. Using linked administrative databases, the impact of anxiety and depression disorders (alone and co-morbid), as diagnosed by a physician, on the probability of sustained RTW following lost-time upper limb or spine strain or sprain work injury was examined for both men and women in stratified models. These relationships were examined using multivariable models adjusted for known and potential confounders. Up to two years of follow-up data was used to identify sustained return to non-modified job duties with no further recurrence of lost-time associated with the claim.

\section{Methods}

\section{Study sample}

A retrospective population-based cohort study was conducted using linked administrative data from the provincial workers' compensation (WorkSafeBC) and public health care (Ministry of Health) systems (22-26). During the study period, $93-95 \%$ of British Columbian workers were covered by workers' compensation (27) and registration in the public health plan was mandatory for all residents. Accepted lost-time claims for upper limb or spine strain/sprain [International Classification for Disease version 9 (ICD-9) codes 840, 841, 842, 846, and 847 (28)] from 2009 to 2013, for workers aged 19-64 years of age, and registered in the provincial public health care plan were selected ( $\mathrm{N}=96870)$. To increase the probability that claims in the reference group did not have anxiety or depression, 7967 (8.2\%) claims with an anxiety or depression-related healthcare event that did not meet the case definitions (described below) in the year before injury were excluded. Of the remaining 88903 claims, 3987 (4.5\%) were excluded due to missing data. The final study sample consisted of 84925 claims.

\section{Study variables}

Outcome variable. Sustained RTW was defined as the number of days from injury date to the date where the worker returned to non-modified or full job duties and hours (based on their pre-injury job duties and hours), and had no further wage loss benefits or modified work days associated with the claim for at least 365 days (supplementary material, www.sjweh.fi/show_abstract. php?abstract_id=3951, figure S1). Two years of followup data were used to determine sustained RTW, prior to censoring at 365 calendar days. By censoring, up to 
365 total disability days of observation following injury were included in the analytic models, but a full 730 day window was used to ensure sustained RTW (supplementary figure $\mathrm{S} 1$ ).

Primary explanatory variable. Claims were classified as having anxiety only, depression only, co-morbid anxiety and depression, or none (no anxiety and no depression) in the year prior to injury. Claims meeting one of the following conditions were classified as depression (i) a hospitalization index event with a depression diagnosis, (ii) an anti-depressant index event and a physician or hospital visit with a depression diagnosis within 12 months of the anti-depressant index event, or (iii) a physician index visit with a depression diagnosis and a second physician or hospital visit for depression, or an anti-depressant event within 12 months of the index visit. Only index events occurring in the 365 days prior to injury were considered. Similar rules were used to classify anxiety, with the exception that anxiety diagnoses were used and dispensing events included anxiolytics in addition to anti-depressants. Both anxiolytics and anti-depressants are common treatments for anxiety disorders and anti-depressants are a recommended firstline pharmacotherapy agent for panic disorders, social anxiety disorders, and generalized anxiety disorders 29 , 30). The Anatomical Therapeutic Chemical classification system was used to identify Anxiolytics (N05B) and Anti-depressants (N06A) (31) while the ICD-9 and ICD-10 systems were used to identify anxiety (ICD-9 300, 308, 309; ICD-10 F4, F68, F341) and depression (ICD-9 311, 296; ICD-10 F3 [F341 excluded]) diagnoses. Lastly, diagnostic code 50b (anxiety/depression) unique to British Columbian physician billing claims was also included as a diagnosis for both anxiety and depression. New onset anxiety and depression disorders occurring after injury but before sustained RTW were also identified in workers with no anxiety or depression related healthcare events in the year prior to injury.

\section{Potential confounders}

Potential confounders included: (i) sociodemographic characteristics: gender, age, income, dependents in the home; (ii) injury characteristics: body part, incident type, secondary diagnosis on the claim; (iii) clinical characteristics: somatic co-morbidity, other mental comorbidity (not including anxiety or depression), and prior claims; and (iv) work characteristics: firm size and occupation (see table 1 for detailed variable categories). Somatic comorbidity was measured as the number of ICD-9 disease categories represented in diagnoses from physician and hospital visits in the year before injury (mental diagnoses and diagnoses identical to the primary diagnoses on the claim excluded) (32).
Table 1. Characteristics of lost-time upper limb or spine strain or sprain claims in British Columbia by gender, 2009-2013

\begin{tabular}{|c|c|c|}
\hline & Men (N=48951) & Women $(\mathrm{N}=35$ 974) \\
\hline & $\mathrm{N}(\%)^{\text {a }}$ & $\mathrm{N}(\%)^{\text {a }}$ \\
\hline \multicolumn{3}{|l|}{$\begin{array}{l}\text { Prevalent anxiety or depression } \\
\text { in the year before injury }\end{array}$} \\
\hline None & 41856 (85.5) & 24691 (68.6) \\
\hline Anxiety only & $1971(4.0)$ & $3102(8.6)$ \\
\hline Depression only & $1483(3.0)$ & $2028(5.6)$ \\
\hline Anxiety \& depression & $3641(7.4)$ & $6153(17.1)$ \\
\hline \multicolumn{3}{|l|}{$\begin{array}{l}\text { Sustained return to non- } \\
\text { modified work }\end{array}$} \\
\hline No & $9578(19.6)$ & 5307 (14.8) \\
\hline Yes & $39373(80.4)$ & 30667 (85.3) \\
\hline \multicolumn{3}{|l|}{ Age group (years) } \\
\hline $19-24$ & $4967(10.2)$ & $2608(7.3)$ \\
\hline $25-29$ & 5494 (11.2) & $3246(9.0)$ \\
\hline $30-39$ & $11327(23.1)$ & $7280(20.2)$ \\
\hline $40-49$ & $13247(27.1)$ & $11081(30.8)$ \\
\hline $50-59$ & $11365(23.2)$ & $10016(27.8)$ \\
\hline $60-64$ & $2551(5.2)$ & $1743(4.9)$ \\
\hline \multicolumn{3}{|l|}{ Income quartile } \\
\hline 1 : lowest & $8726(17.8)$ & $11836(32.9)$ \\
\hline 2 & $10416(21.3)$ & $10772(29.9)$ \\
\hline 3 & $13497(27.6)$ & $8041(22.4)$ \\
\hline 4: highest & 16312 (33.3) & $5325(14.8)$ \\
\hline \multicolumn{3}{|l|}{ Dependents } \\
\hline 0 & $33083(67.6)$ & $22939(63.8)$ \\
\hline$\geq 1$ & $15868(32.4)$ & $13035(36.2)$ \\
\hline \multicolumn{3}{|l|}{ Injured body part } \\
\hline Spine & $14460(29.6)$ & $11584(32.2)$ \\
\hline Upper limb & $34491(70.5)$ & $24390(67.8)$ \\
\hline \multicolumn{3}{|l|}{ Incident type } \\
\hline Exertion & $826(1.7)$ & $1948(5.4)$ \\
\hline Traumatic & $7669(15.7)$ & $6386(17.8)$ \\
\hline Fall/slip/trip & $10344(21.1)$ & $8858(24.6)$ \\
\hline Contact object & 24042 (49.1) & $15542(43.2)$ \\
\hline Transportation & $2650(5.4)$ & $2034(5.7)$ \\
\hline Bodily motion & $3420(7.0)$ & $1206(3.4)$ \\
\hline \multicolumn{3}{|l|}{$\begin{array}{l}\text { Secondary diagnosis on the } \\
\text { claim }\end{array}$} \\
\hline No & $41589(85.0)$ & $27877(77.5)$ \\
\hline Yes $^{b}$ & $7362(15.0)$ & $8097(22.5)$ \\
\hline \multicolumn{3}{|l|}{ Somatic co-morbidity } \\
\hline 0 & $5796(11.8)$ & $1607(4.5)$ \\
\hline 1 & $9911(20.3)$ & $3829(10.6)$ \\
\hline 2 & $10702(21.9)$ & $6174(17.2)$ \\
\hline 3 & 9432 (19.3) & $7014(19.5)$ \\
\hline$\geq 4$ & $13110(26.8)$ & $17350(48.2)$ \\
\hline \multicolumn{3}{|l|}{ Mental co-morbidity ${ }^{\mathrm{b}}$} \\
\hline 0 & $46755(95.5)$ & 34509 (95.9) \\
\hline$\geq 1$ & $2196(4.5)$ & $1465(4.1)$ \\
\hline \multicolumn{3}{|l|}{ Prior claims } \\
\hline 0 & $17904(36.6)$ & $16032(44.6)$ \\
\hline$\geq 1$ & $31047(63.4)$ & $19942(55.4)$ \\
\hline \multicolumn{3}{|l|}{ Firm size (employees) } \\
\hline$\leq 30$ & 15602 (31.9) & $5029(14.0)$ \\
\hline $31-150$ & $12516(25.6)$ & $6910(19.2)$ \\
\hline $151-1000$ & $11074(22.6)$ & $8053(22.4)$ \\
\hline$\geq 1001$ & 9759 (19.9) & $15982(44.4)$ \\
\hline \multicolumn{3}{|l|}{ Occupation } \\
\hline Sales and services & $7165(14.6)$ & 12651 (35.2) \\
\hline Art, culture, recreation & $415(0.9)$ & $499(1.4)$ \\
\hline Business, finance, admin & $2086(4.3)$ & $1975(5.5)$ \\
\hline Health & $2072(4.2)$ & $13119(36.5)$ \\
\hline Management & $834(1.7)$ & $876(2.4)$ \\
\hline Natural/applied sciences & $1441(2.9)$ & $273(0.8)$ \\
\hline Primary industry & 1595 (3.3) & $372(1.0)$ \\
\hline Processing, utilities & $4809(9.8)$ & $1303(3.6)$ \\
\hline Social science, government & $764(1.6)$ & $2766(7.7)$ \\
\hline Trades, transport & $27770(56.7)$ & $2140(6.0)$ \\
\hline
\end{tabular}

${ }^{a}$ Column percentages may not equal $100 \%$ due to rounding.

${ }^{\mathrm{b}}$ Not anxiety or depression. 


\section{Analyses}

Descriptive statistics were used to examine the injured worker cohort by socio-demographic, injury, clinical, and work-related characteristics overall and by preinjury mental health status for both men and women. All analyses were conducted using SAS software, version 9.4 (SAS Institute, Cary, NC, USA).

Impact of pre-existing anxiety and depression prevalent in the year prior to injury

Unadjusted and adjusted Cox models (33) stratified by gender were used to examine the impact of anxiety and depression disorders from the year before injury on the probability of sustained RTW by calculating hazard ratios (HR) with $95 \%$ confidence intervals (CI). The proportionality assumption was tested for the anxiety and depression variable using Kaplan-Meier curves and by testing for interaction with the log of the time variable (number of days since injury) in the Cox models. No evidence of non-proportionality was found. Confounder strength was analyzed by examining the change in the anxiety and depression hazard ratio estimates when individual confounders were added to the unadjusted models. Only minor changes were observed $(<10 \%$ change $)$ (data not shown). The strongest confounder in the men's and women's models was somatic co-morbidity with a change of $<4 \%$ for each HR respectively.

While multiplicative Cox models are the most common tool for analyzing time to event data with censoring in observational epidemiology, additive effect measures are more easily interpreted and policy relevant. To address this, the impact of pre-existing anxiety and depression disorders prevalent in the year before injury were examined on the additive scale using directadjusted survival curves and life table methods stratified by gender (34). Using this method, unadjusted and adjusted median times to sustained RTW and interquartile ranges were calculated by anxiety and depression case status in the year before injury. Censoring the sustained RTW variable at 365 days did not affect the median or interquartile range estimates, as these values were all $<365$.

Effect modification of the primary relationship between pre-existing anxiety and depression on sustained RTW by gender was examined on the multiplicative and additive scales. For the multiplicative scale, the ratio of ratios was calculated for the mental health variable within strata of the gender/sex variable (women's HR: men's HR) (35). For the additive scale, the relative excess risk due to interaction (RERI) was calculated (36).
Impact of new onset anxiety and depression occurring during the RTW period

The impact of new onset anxiety and/or depression on the probability of sustained RTW was also examined. Cox models stratified by gender, adjusted for all confounders were replicated with a study sample restricted to workers with no anxiety or depression related health care events in the year prior to injury. The anxiety or depression variable was time varying but once a claim was classified as having anxiety only, depression only, or co-morbid anxiety and depression, it remained in this classification until the end of follow-up. The median time to case onset for workers who developed a new anxiety or depression episode during the RTW period was calculated.

\section{Results}

The study sample included 48951 men and 35974 women (table 1). The majority of claims for both men $(85.5 \%)$ and women $(68.6 \%)$ had no anxiety and no depression (ie, 'none') in the year before injury. The prevalence of anxiety only, depression only, and anxiety and depression in the year before injury was approximately twice as high among women $(8.6 \%, 5.6 \%$, and $17.1 \%$ respectively) than men $(4.0 \%, 3.0 \%$, and $7.4 \%)$. The majority of claims reached sustained RTW within 365 days (men $80.4 \%$; women $85.3 \%$ ).

\section{Impact of pre-existing anxiety and depression prevalent in} the year prior to injury

In the unadjusted Cox models, compared to workers with no anxiety and no depression in the year prior to injury, workers with anxiety only (men HR $0.85,95 \%$ CI 0.80 0.89, women HR $0.94,95 \%$ CI $0.90-0.98$ ), depression only (men HR $0.91,95 \%$ CI 0.86-0.97, women HR 0.96 , 95\% CI 0.92-1.01), or co-morbid anxiety and depression (men HR $0.89,95 \%$ CI 0.86-0.93, women HR 0.93 , $95 \%$ CI $0.90-0.96$ ) had lower probability of sustained RTW (table 2 and supplementary table S1). Similar but attenuated associations were observed in the adjusted Cox models with all potential confounders, although the $95 \%$ CI around the estimates included ' 1 ' for depression only in the both the men's and women's models.

The unadjusted median time to sustained RTW was 34 days for men with no anxiety and no depression, and 52,43 , and 45 days for men with anxiety only, depression only, and co-morbid anxiety and depression (table 3). Stated differently, compared to men with no anxiety and no depression, men with anxiety only, depression only, and co-morbid anxiety and depression took 18, 9, 
Table 2. Probability of sustained return work by gender, multiplicative Cox regression models. [HR=hazard ratio; $\mathrm{Cl}=$ confidence interval; $\mathrm{RERI}=$ relative excess risk due to interaction]

\begin{tabular}{|c|c|c|c|c|c|c|}
\hline \multirow[b]{3}{*}{$\begin{array}{l}\text { Prevalent anxiety or } \\
\text { depression in the year } \\
\text { before injury }\end{array}$} & \multicolumn{2}{|c|}{ Men } & \multicolumn{2}{|c|}{ Women } & \multirow{2}{*}{$\begin{array}{c}\text { Ratio of } \\
\text { adjusted } \\
\text { ratios }^{\mathrm{a}, \mathrm{b}}(95 \% \mathrm{Cl})\end{array}$} & \multirow{2}{*}{$\begin{array}{c}\text { Adjusted RERI a, c } \\
(95 \% \mathrm{Cl})\end{array}$} \\
\hline & $\begin{array}{l}\text { Unadjusted } \\
\text { HR (95\% Cl) }\end{array}$ & $\begin{array}{l}\text { Adjusted a } \\
\text { HR (95\% Cl) }\end{array}$ & $\begin{array}{l}\text { Unadjusted } \\
\text { HR (95\% Cl) }\end{array}$ & $\begin{array}{l}\text { Adjusted a } \\
\text { HR (95\% Cl) }\end{array}$ & & \\
\hline & & & & & & \\
\hline None & 1 & 1 & 1 & 1 & & \\
\hline Anxiety only & $0.85(0.80-0.89)$ & $0.88(0.84-0.93)$ & $0.94(0.90-0.98)$ & $0.95(0.92-0.99)$ & 1.09 (1.02-1.17) & $0.08(0.02-0.14)$ \\
\hline Depression only & $0.91(0.86-0.97)$ & $0.94(0.89-1.00)$ & $0.96(0.92-1.01)$ & $0.98(0.93-1.03)$ & $1.05(0.97-1.13)$ & $0.04(-0.03-0.11)$ \\
\hline Anxiety \& depression & $0.89(0.86-0.93)$ & $0.93(0.90-0.97)$ & $0.93(0.90-0.96)$ & $0.94(0.91-0.97)$ & $1.02(0.97-1.07)$ & $0.01(-0.03-0.06)$ \\
\hline
\end{tabular}

Table 3. Days to sustained return to work by anxiety and depression in the year before injury and gender, additive survival curves. [IQR=interquartile range.]

\begin{tabular}{|c|c|c|c|c|}
\hline & \multicolumn{2}{|c|}{ Men } & \multicolumn{2}{|c|}{ Women } \\
\hline & $\begin{array}{c}\text { Unadjusted } \\
\text { Median (IQR) } \\
\end{array}$ & $\begin{array}{c}\text { Adjusted }{ }^{\mathrm{a}} \\
\text { Median (IQR) }\end{array}$ & $\begin{array}{c}\text { Unadjusted } \\
\text { Median (IQR) }\end{array}$ & $\begin{array}{c}\text { Adjusted }^{\text {a }} \\
\text { Median (IQR) }\end{array}$ \\
\hline \multicolumn{5}{|c|}{$\begin{array}{l}\text { Prevalent anxiety or depression in the } \\
\text { year before injury }\end{array}$} \\
\hline None & $34(10-149)$ & $34(10-152)$ & $40(10-109)$ & $40(10-110)$ \\
\hline Anxiety only & $52(12-313)$ & $49(12-274)$ & $46(11-125)$ & $45(11-124)$ \\
\hline Depression only & $43(12-201)$ & $42(11-182)$ & $42(11-115)$ & $42(10-115)$ \\
\hline Anxiety \& depression & $45(11-238)$ & $42(11-215)$ & $44(11-125)$ & $44(11-124)$ \\
\hline
\end{tabular}

and 11 days longer, respectively, to reach sustained RTW. The same pattern for the unadjusted median time to sustained RTW by baseline exposure status was observed for women, but the unadjusted absolute differences between the no anxiety and no depression group and the case groups were less pronounced (no anxiety and no depression 40 days, anxiety only 46 days, depression only 42 days, co-morbid anxiety and depression 44 days). Women with anxiety only, depression only, and co-morbid anxiety and depression took 6,2 , and 4 days longer to reach sustained RTW than women with no anxiety and no depression, respectively. Similar results were found in the direct adjusted survival curves with all potential confounders but the effects of anxiety and depression were attenuated. After adjustment for potential confounders, men with anxiety only, depression only, and co-morbid anxiety and depression took 15,8 , and 8 days longer to reach sustained RTW than men with no anxiety and no depression, respectively; and these same corresponding values for women were 5, 2, and 4 days longer.

The ratio of ratio estimate's for the mental health variable within strata of the gender/sex variable (women's HR: men's HR) were all $>1$ (anxiety only $1.09,95 \%$ CI 1.02-1.07, depression only $1.05,95 \%$ CI $0.97-1.13$, anxiety and depression 1.02, 95\% CI 0.97-1.07), but only the estimate for anxiety only had a $95 \%$ CI that excluded ' 1 ' (table 2). This means that the effect size of the relationship between anxiety only and sustained RTW in women was 1.09 times smaller (ie, closer to 1) than would have been expected based on the effect size of this relationship in men. In other words, while anxiety only (compared to no anxiety and no depression) was associated with a lower probability of sustained RTW for both women and men on the multiplicative scale, the strength of this relationship was significantly greater for men than for women (ie, men experienced a lower probability of sustained RTW attributable to anxiety than women, even though anxiety was associated with a lower probability of RTW in women as well). Similar results were found on the additive scale with the RERI indicating that the effects of anxiety only on the lower probability of sustained RTW were significantly greater for men than women, and the negative effects of depression only and co-morbid anxiety and depression were non-significantly greater for men than women (table 2).

\section{Impact of new onset anxiety and depression occurring during the RTW period}

For both men and women, new onset anxiety only (men HR 0.82 , 95\% CI 0.72-0.95, women HR 0.89, 95\% CI 0.79-1.01), depression only (men HR 0.69 , 95\% CI 0.56-0.86, women HR 0.72, 95\% CI 0.58-0.90,), and co-morbid anxiety and depression (men HR: 0.63, 95\% 
CI $0.54-0.74$, women HR $0.65,95 \%$ CI $0.57-0.74$ ) that developed after injury but before sustained RTW were associated with lower probability of sustained RTW, in Cox models adjusted for confounders (table 4). New onset anxiety only, depression only and anxiety and depression were associated with lower probability of sustained RTW for both men and women, but the effect sizes were descriptively greater for men. This is indicated by the lower adjusted hazard ratio (further away from 1 and $<1$ ) for men compared to women (table 4).

\section{Discussion}

\section{Summary of main findings}

For men and women, pre-existing and new onset anxiety only, depression only, and co-morbid anxiety and depression were consistently associated with lower probability of sustained RTW after lost-time upper limb or spine strain or sprain work injury. For pre-existing disorders, anxiety only was associated with the longest time to sustained RTW in both men and women, however, the number of excess days attributable to pre-existing anxiety only (compared to no anxiety and no depression) was greater for men than women (an excess of 15 calendar days for men versus 5 for women). A similar direction of this gendered effect was observed for all other preexisting and new onset disorders, although in some cases, the magnitude of the difference between men and women was small or not statistically significant. Lastly, new onset disorders had a larger detrimental impact on RTW than pre-existing disorders for both men and women.

\section{Anxiety and depression and RTW}

The current findings are consistent with the broader psychiatric and disability literature where anxiety and depression disorders are risk factors for work disability (37-43), including a prospective cohort study on depressive symptoms in workers with work-related musculoskeletal strain or sprain (18). However, they are not consistent with a 2008 systematic review by Iles et al (12) where depression and anxiety were not predictive of work outcomes after non-chronic, non-specific low back pain. This discrepancy could be due to methodological limitations of previous research including small sample sizes, short follow-up time, and the use of a work outcome variable that does not capture lost-time recurrence (12). Differences in study sample selection and anxiety and depression measurement methods may also explain differences in findings. For the latter, scale measures of self-reported anxiety and depressive symptoms capture a separate mental construct than clinical diagnoses.

As anxiety and depression disorders have overlapping symptom profiles (44) the mechanisms that link these disorders to poor RTW outcomes after musculoskeletal injury are hypothesized to be similar. These include: (i) increased pain due to shared neuroanatomical pathways and neurotransmitters $(5,6)$; (ii) activity disruption or a general loss of interest in activities that promote well-being and RTW processes (8); (iii) resistance or non-adherence to musculoskeletal injury therapeutic treatment (7); (iv) self-assessed inability to perform work tasks effectively (9) due to symptoms like fatigue, worry, or worthlessness, especially in the context of returning to a work environment that caused musculoskeletal injury; (v) difficulty navigating social interactions involved in the RTW process possibly due to mental health stigma or a negative response to mental symptoms by others (11); (vi) exacerbation of mental symptoms by procedural aspects of the workers' compensation experience such as adjudication decisions and medical assessments (10); and (vii) a greater need for work accommodation due to the compounding effects of mental symptoms in combination with physical ones. It is hypothesized here that these potential mechanisms

Table 4. Frequency and timing of new onset anxiety and depression disorders and impact on sustained return to work (RTW) by gender, multiplicative Cox models. [IQR=interquartile range; $\mathrm{HR}=$ hazard ratio; $\mathrm{Cl}=$ confidence interval.]

\begin{tabular}{|c|c|c|c|c|c|c|c|c|}
\hline & \multicolumn{4}{|c|}{ Men (N=41 856) } & \multicolumn{4}{|c|}{ Women ( $\mathrm{N}=24$ 691) } \\
\hline & $\begin{array}{l}\text { New onset } \\
\text { disorder }\end{array}$ & $\begin{array}{l}\text { Days to } \\
\text { disorder } \\
\text { onset }\end{array}$ & $\begin{array}{l}\text { Unadjusted HR } \\
(95 \% \mathrm{CI}) \text { to } \\
\text { sustained RTW }\end{array}$ & $\begin{array}{c}\text { Adjusted a HR } \\
(95 \% \mathrm{Cl}) \text { to } \\
\text { sustained RTW }\end{array}$ & $\begin{array}{l}\text { New onset } \\
\text { disorder }\end{array}$ & $\begin{array}{l}\text { Days to } \\
\text { disorder } \\
\text { onset }\end{array}$ & $\begin{array}{l}\text { Unadjusted HR } \\
(95 \% \mathrm{Cl}) \text { to } \\
\text { sustained RTW }\end{array}$ & $\begin{array}{c}\text { Adjusted }{ }^{\text {a }} \mathrm{HR} \\
(95 \% \mathrm{Cl}) \text { to } \\
\text { sustained RTW }\end{array}$ \\
\hline & $\mathrm{N}(\%)$ & $\overline{\text { Median (IQR) }}$ & $\mathrm{HR}(95 \% \mathrm{Cl})$ & $\mathrm{HR}(95 \% \mathrm{Cl})$ & $\mathrm{N}(\%)$ & $\overline{\text { Median (IQR) }}$ & $\operatorname{HR}(95 \% \mathrm{Cl})$ & $\mathrm{HR}(95 \% \mathrm{Cl})$ \\
\hline \multicolumn{9}{|l|}{$\begin{array}{l}\text { New onset anxiety or } \\
\text { depression }\end{array}$} \\
\hline None & 40503 (96.8) & & 1 & 1 & 23492 (95.1) & & 1 & 1 \\
\hline Anxiety only & $522(1.3)$ & $78(26-180)$ & $0.82(0.71-0.94)$ & $0.82(0.71-0.94)$ & $503(2.0)$ & $77(29-164)$ & $0.89(0.78-1.01)$ & $0.88(0.78-1.00)$ \\
\hline Depression only & $272(0.7)$ & $104(38-194)$ & $0.71(0.57-0.88)$ & $0.69(0.56-0.85)$ & $199(0.8)$ & $99(36-192)$ & $0.74(0.59-0.92)$ & $0.72(0.58-0.90)$ \\
\hline Anxiety \& depression & 559 (1.3) & $97(38-186)$ & $0.65(0.56-0.76)$ & $0.63(0.54-0.74)$ & $497(2.0)$ & $67(22-145)$ & $0.65(0.57-0.75)$ & $0.65(0.56-0.74)$ \\
\hline
\end{tabular}

${ }^{a}$ Adjusted for age group, income quintile, dependents, injured body part, incident type, secondary diagnosis on the claim, somatic co-morbidity index score, other mental co-morbidity (that is not anxiety or depression), prior claims, firm size, occupation. 
likely play a role for both pre-existing and new onset anxiety and depression disorders, however the extent of their impacts are likely greater for new onset disorders due to the lack of an existing treatment plan and the absence of coping strategies.

\section{Gender differences}

The finding that the detrimental impact of pre-existing anxiety on RTW is significantly greater for men than for women is similar to a study of short-term disability leave for non-occupational depression where men were less likely to RTW than women (45). One hypothesis for the current finding is lower use of anxiety treatments after diagnosis among men compared to women that would otherwise buffer the potential negative effects of anxiety on RTW, as well as buffer the negative mental health effects of a significant life event such as being injured and off work/on disability benefits. Other hypotheses as proposed by Scott (20) include: (i) men's high occupational performance expectations in combination with anxiety symptoms (eg, fear or worry) that may lead men with anxiety to self-assess themselves as unable to work; (ii) men may be less likely to disclose negative emotions related to an episode of anxiety that in turn may create feelings of isolation or less opportunities for mental health support; and (iii) men may have smaller social support networks than women that may also lead to less opportunities for mental health support during a significant health/life event, although the evidence for this latter point is mixed (20). Lastly, evidence suggests that men with work injury in British Columbia have fewer graduated RTW options than women (46). A longer detachment from the workplace (due to an absence of graduated RTW and thus an absence of the therapeutic effects of work) may facilitate the bi-directional relationships of anxiety with work disability, resulting in longer time to sustained RTW.

\section{Strengths and limitations}

Strengths of the current study include the use of a longitudinal population-based dataset, measures of anxiety and depression diagnoses from before and after injury based on health claims data, a two year follow-up period, minimal loss to follow-up, and use of a RTW outcome that accounts for recurring lost-time. Despite this, there are some potential limitations. First, workers with an anxiety or depression disorder could be misclassified as not having the disorder due to under treatment and under diagnoses of these disorders, or use of private mental health services (not captured in the public health claims data). This would have resulted in an underestimation of the main effects observed in the current study. Building on this issue, differential misclassification of workers with depression or anxiety by gender could have contributed to the findings for gender modification. Men are less likely to receive anxiety or depression treatment from a general practitioner than women but equally as likely to receive treatment from a specialist $(47-50)$. It is unknown if this phenomenon is due to (i) lower incidence of mild anxiety and depression in men compared to women, (ii) under treatment of mild anxiety and depression in men, (iii) a higher likelihood of referral to a mental health specialist for men, (iv) delayed treatment among men resulting in more severe cases by the time of diagnosis, or (v) a combination of these making it difficult to ascertain how this might impact the current study. To minimize these biases, workers with an anxiety or depression health care event not sufficient to meet the case definitions were excluded. These excluded workers likely represent potential false positives or mild or transient cases. Lastly, as with all observational study designs, despite adjustment for a range of sociodemographic, clinical, injury and work-related potential confounders, there remains the possibility of some residual confounding.

\section{Concluding remarks}

Workers' compensation benefits and programs intended to improve RTW after lost-time upper limb or spine strain or sprain work injury should take pre-existing anxiety and depression disorders into consideration, in addition to new onset disorders attributable to the injury; and, gender-sensitive strategies may be warranted to optimize RTW outcomes. Based on these findings, further investigation of how anxiety and depression affect RTW processes and transitions, during the time course from injury to sustained RTW, and the identification of gender-sensitive strategies to address this, is warranted.

\section{Acknowledgments}

Andrea Marie Jones was supported by a WorkSafeBC Research Training Award, Centre for Research on Work Disability Policy Student Trainee Award, and Bridge Canadian Institutes for Health Research (CIHR) Strategic Training Fellowship. Mieke Koehoorn was supported in part by a CIHR Chair in Gender, Work and Health. Christopher McLeod was supported by a CIHR New Investigator Award and is supported by a Michael Smith Foundation for Health Research Scholar Award. Andrea Marie Jones, Mieke Koehoorn, and Christopher McLeod are supported by research operating funds through the Partnership for Work Health and Safety - a research partnership between WorkSafeBC (the provincial workers' compensation system) and the University of British Columbia. 


\section{Disclaimer}

All inferences, opinions, and conclusions drawn in this paper are those of the authors, and do not reflect the opinions or policies of the Data Stewards.

\section{Conflict of interest}

The authors declare no conflicts of interest.

\section{References}

1. WorkSafeBC. Statistics 2018;2019:69. [cited 2020 Jun 7] Available from: https://www.worksafebc.com/en/resources/ about-us/annual-report-statistics/2018-stats?lang=en

2. Dersh J, Gatchel RJ, Polatin P, Mayer T. Prevalence of psychiatric disorders in patients with chronic work-related musculoskeletal pain disability. J Occup Environ Med 2002 May;44(5):459-68. https://doi.org/10.1097/00043764200205000-00014.

3. Dersh J, Gatchel RJ, Mayer T, Polatin P, Temple OR. Prevalence of psychiatric disorders in patients with chronic disabling occupational spinal disorders. Spine 2006 May;31(10):1156-62. https://doi.org/10.1097/01. brs.0000216441.83135.6f.

4. Dersh J, Mayer T, Theodore BR, Polatin P, Gatchel RJ. Do psychiatric disorders first appear preinjury or postinjury in chronic disabling occupational spinal disorders? Spine 2007 Apr;32(9):1045-51. https://doi.org/10.1097/01. brs.0000261027.28779.52.

5. Han C, Pae CU. Pain and depression: a neurobiological perspective of their relationship. Psychiatry Investig 2015 Jan;12(1):1-8. https://doi.org/10.4306/pi.2015.12.1.1.

6. Theunissen M, Peters ML, Bruce J, Gramke HF, Marcus MA. Preoperative anxiety and catastrophizing: a systematic review and meta-analysis of the association with chronic postsurgical pain. Clin J Pain 2012 Nov-Dec;28(9):819-41. https://doi.org/10.1097/AJP.0b013e31824549d6.

7. Slepian P, Bernier E, Scott W, Niederstrasser NG, Wideman T, Sullivan M. Changes in pain catastrophizing following physical therapy for musculoskeletal injury: the influence of depressive and post-traumatic stress symptoms. J Occup Rehabil 2014 Mar;24(1):22-31. https://doi.org/10.1007/ s10926-013-9432-2.

8. Sullivan MJ, Simmonds M, Velly A. Pain, depression, disability and rehabilitation outcomes. Revised version. Institut de recherche Robert-Sauvé en santé et en sécurité du travail (IRSST). 2011. Available from: https://www.irsst. qc.ca/media/documents/PubIRSST/R-675.pdf. [Accessed 7 Jun 2020].

9. Petrie KJ, Weinman J, Sharpe N, Buckley J. Role of patients' view of their illness in predicting RTW and functioning after myocardial infarction: longitudinal study. BMJ 1996 May;312(7040):1191-4. https://doi.org/10.1136/

bmj.312.7040.1191

10. Sullivan MJ, Scott W, Trost Z. Perceived injustice: a risk factor for problematic pain outcomes. Clin J Pain 2012 Jul;28(6):484-8. https://doi.org/10.1097/ AJP.0b013e3182527d13

11. Stuart H. Mental illness and employment discrimination. Curr Opin Psychiatry 2006 Sep;19(5):522-6. https://doi. org/10.1097/01.yco.0000238482.27270.5d.

12. Iles RA, Davidson M, Taylor NF. Psychosocial predictors of failure to RTW in non-chronic non-specific low back pain: a systematic review. Occup Environ Med 2008 Aug;65(8):507-17. https://doi.org/10.1136/ oem.2007.036046.

13. Shaw WS, Pransky G, Fitzgerald TE. Early prognosis for low back disability: intervention strategies for health care providers. Disabil Rehabil 2001 Dec;23(18):815-28. https:// doi.org/10.1080/09638280110066280.

14. Steenstra IA, Verbeek JH, Heymans MW, Bongers PM Prognostic factors for duration of sick leave in patients sick listed with acute low back pain: a systematic review of the literature. Occup Environ Med 2005 Dec;62(12):851-60. https://doi.org/10.1136/oem.2004.015842.

15. Kuijer W, Groothoff JW, Brouwer S, Geertzen JH, Dijkstra PU. Prediction of sickness absence in patients with chronic low back pain: a systematic review. J Occup Rehabil 2006 Sep;16(3):439-67. https://doi.org/10.1007/s10926-0069021-8.

16. Kent PM, Keating JL. Can we predict poor recovery from recent-onset nonspecific low back pain? A systematic review. Man Ther 2008 Feb;13(1):12-28. https://doi. org/10.1016/j.math.2007.05.009.

17. Clay FJ, Newstead SV, McClure RJ. A systematic review of early prognostic factors for RTW following acute orthopaedic trauma. Injury 2010 Aug;41(8):787-803. https://doi.org/10.1016/j.injury.2010.04.005.

18. Carnide N, Franche RL, Hogg-Johnson S, Côté P, Breslin FC, Severin $\mathrm{CN}$ et al. Course of depressive symptoms following a workplace injury: a 12-month follow-up update. J Occup Rehabil 2016 Jun;26(2):204-15. https://doi. org/10.1007/s10926-015-9604-3.

19. Laisné F, Lecomte C, Corbière M. Biopsychosocial determinants of work outcomes of workers with occupational injuries receiving compensation: a prospective study. Work 2013;44(2):117-32. https://doi.org/10.3233/WOR-20121378.

20. Scott KM. Sex differences in the disability associated with mental disorders. Curr Opin Psychiatry 2011 Jul;24(4):3315. https://doi.org/10.1097/YCO.0b013e3283477ad5.

21. Moyser M, Burlock A. Time use: total work burden, unpaid work, and leisure. Statistics Canada. 2018. Available from: https://www150.statcan.gc.ca/n1/pub/89-503-x/2015001/ article/54931/c-g/c-g01-eng.htm. [Accessed 1 Aug 2019].

22. WorkSafeBC [creator] (2016). WorkSafeBC claims and firm level files. Population Data BC [publisher]. Data extract. WorkSafeBC (2016). Available from: http://www.popdata. bc.ca/data. 
23. BC Ministry of Health [creator] (2017). PharmaNet. BC Ministry of Health [publisher]. Data extract. Data Stewardship Committee (2016). [Available from: http:// www.popdata.bc.ca/data].

24. BC Ministry of Health [creator] (2017). Medical services plan (MSP) payment information file. Population Data BC [publisher]. Data dxtract. MOH (2016). Available from http://www.popdata.bc.ca/data.

25. BC Ministry of Health [creator] (2017). Consolidation file (MSP registration \& premium billing). Population Data BC [publisher]. Data extract. MOH (2016). Available from: http://www.popdata.bc.ca/data

26. Canadian Institute for Health Information [creator] (2017). Discharge abstract database (hospital separations). Population Data BC [publisher]. Data extract. MOH (2016). Available from: http://www.popdata.bc.ca/data.

27. Association of Workers' Compensation Boards of Canada. Detailed key statistical measures report 2009 to 2013 [database online]. 2018. Available from: http://awcbc. org/?page_id=9755. [Accessed 7 Jun 2020].

28. World Health Organization. International classification of diseases: [9th] ninth revision, basic tabulation list with alphabetic index. 1978. Available from: https://apps.who. int/iris/handle/10665/39473. [Accessed 21 Mar 2020].

29. Katzman MA, Bleau P, Blier P, Chokka P, Kjernisted K, Van Ameringen $\mathrm{M}$ et al.; Canadian Anxiety Guidelines Initiative Group on behalf of the Anxiety Disorders Association of Canada/Association Canadienne des troubles anxieux and McGill University. Canadian clinical practice guidelines for the management of anxiety, posttraumatic stress and obsessive-compulsive disorders. BMC Psychiatry 2014;14 Suppl 1:S1. https://doi.org/10.1186/1471-244X-14-S1-S1.

30. Lam RW, McIntosh D, Wang J, Enns MW, Kolivakis T, Michalak EE et al.; CANMAT Depression Work Group. Canadian Network for Mood and Anxiety Treatments (CANMAT) 2016 clinical guidelines for the management of adults with major depressive disorder: section 1. Disease burden and principles of care. Can J Psychiatry 2016 Sep;61(9):510-23. https://doi. org/10.1177/0706743716659416.

31. World Health Organization. Anatomical Therapeutic Chemical (ATC) Classification. WHO Collaborating Centre for Drug Statistics Methodology. 2011. Available from: https://www.whocc.no/atc/structure_and_principles/. [Accessed 9 Jan 2018].

32. Cameron CM, Purdie DM, Kliewer EV, McClure RJ. Differences in prevalence of pre-existing morbidity between injured and non-injured populations. Bull World Health Organ 2005 May;83(5):345-52.

33. Cox DR. Regression models and life-tables. J R Stat Soc [Ser A] 1972;34(2):187-220. https://doi. org/10.1111/j.2517-6161.1972.tb00899.x.

34. Zhang X, Loberiza FR, Klein JP, Zhang MJ. A SAS macro for estimation of direct adjusted survival curves based on a stratified Cox regression model. Comput Methods Programs Biomed 2007 Nov;88(2):95-101. https://doi.org/10.1016/j. cmpb.2007.07.010.
35. Knol MJ, VanderWeele TJ. Recommendations for presenting analyses of effect modification and interaction. Int J Epidemiol 2012 Apr;41(2):514-20. https://doi. org/10.1093/ije/dyr218.

36. Li R, Chambless L. Test for additive interaction in proportional hazards models. Ann Epidemiol 2007 Mar;17(3):227-36. https://doi.org/10.1016/j.annepidem.2006.10.009.

37. Zieger M, Luppa M, Meisel HJ, Günther L, Winkler D, Toussaint $\mathrm{R}$ et al. The impact of psychiatric comorbidity on the RTW in patients undergoing herniated disc surgery. J Occup Rehabil 2011 Mar;21(1):54-65. https://doi. org/10.1007/s10926-010-9257-1.

38. Lavoie KL, Favreau H, Paine NJ, Lemière C, Joseph M, Gagnon-Chauvin A et al. Prospective impact of psychiatric disorders on employment status and health care use in patients investigated for occupational asthma. J Occup Environ Med 2016 Dec;58(12):1196-201. https://doi. org/10.1097/JOM.0000000000000886.

39. Stein MB, Cox BJ, Afifi TO, Belik SL, Sareen J. Does comorbid depressive illness magnify the impact of chronic physical illness? A population-based perspective. Psychol Med 2006 May;36(5):587-96. https://doi.org/10.1017/ S0033291706007239.

40. Stein MB, Roy-Byrne PP, Craske MG, Bystritsky A, Sullivan G, Pyne JM et al. Functional impact and health utility of anxiety disorders in primary care outpatients. Med Care 2005 Dec;43(12):1164-70. https://doi.org/10.1097/01. mlr.0000185750.18119.fd.

41. Lim D, Sanderson K, Andrews G. Lost productivity among full-time workers with mental disorders. J Ment Health Policy Econ 2000 Sep;3(3):139-46. https://doi.org/10.1002/ mhp.93.

42. Jefferis BJ, Nazareth I, Marston L, Moreno-Kustner B, Bellón JÁ, Svab I et al. Associations between unemployment and major depressive disorder: evidence from an international, prospective study (the predict cohort). Soc Sci Med 2011 Dec;73(11):1627-34. https://doi. org/10.1016/j.socscimed.2011.09.029.

43. Waghorn G, Chant D, White P, Whiteford H. Disability, employment and work performance among people with ICD-10 anxiety disorders. Aust N Z J Psychiatry 2005 Jan-Feb;39(1-2):55-66. https://doi.org/10.1080/j.14401614.2005.01510.x.

44. American Psyhiatric Association. Diagnostic and statistical manual of mental disorders. $5^{\text {th }}$ ed. Arlington, VA: American Psychiatric Publishing; 2013.

45. Dewa CS, Goering P, Lin E, Paterson M. Depressionrelated short-term disability in an employed population. $\mathrm{J}$ Occup Environ Med 2002 Jul;44(7):628-33. https://doi. org/10.1097/00043764-200207000-00007.

46. Maas ET, Koehoorn M, McLeod CB. Descriptive epidemiology of gradual RTW for workers with a workacquired musculoskeletal disorder in British Columbia, Canada. J Occup Environ Med 2020 Feb;62(2):113-23. https://doi.org/10.1097/JOM.0000000000001768. 
47. Roberge P, Fournier L, Duhoux A, Nguyen CT, Smolders M. Mental health service use and treatment adequacy for anxiety disorders in Canada. Soc Psychiatry Psychiatr Epidemiol 2011 Apr;46(4):321-30. https://doi.org/10.1007/ s00127-010-0186-2.

48. Gagné S, Vasiliadis HM, Préville M. Gender differences in general and specialty outpatient mental health service use for depression. BMC Psychiatry 2014 May;14(135). https:// doi.org/10.1186/1471-244X-14-135.

49. Smith KL, Matheson FI, Moineddin R, Dunn JR, $\mathrm{Lu} \mathrm{H}$, Cairney $\mathrm{J}$ et al. Gender differences in mental health service utilization among respondents reporting depression in a national health survey. Health (Irvine Calif) 2013;5(10):1561-71. https://doi.org/10.4236/ health.2013.510212.

50. O’Donnell S, Syoufi M, Jones W, Bennett K, Pelletier L. Use of medication and psychological counselling among Canadians with mood and/or anxiety disorders. Health Promot Chronic Dis Prev Can 2017 May;37(5):160-71. https://doi.org/10.24095/hpcdp.37.5.04.

Received for publication: 5 August 2021 